\title{
REMARKS ON THE LINEAR FRACTIONAL INTEGRO-DIFFERENTIAL EQUATION WITH VARIABLE COEFFICIENTS IN DISTRIBUTION
}

\section{CHENKUAN Li AND JiANFEI HUANG}

Abstract. The goal of this paper is to study the following linear fractional integro-differential equation with variable coefficients, for the first time, in the distributional space $\mathscr{D}^{\prime}\left(R^{+}\right)$by Babenko's approach

$$
u^{\left(\beta_{n}\right)}(x)+a_{n-1}(x) u^{\left(\beta_{n-1}\right)}(x)+\cdots+a_{1}(x) u^{\left(\beta_{1}\right)}(x)+a_{0}(x) u^{\left(\beta_{0}\right)}(x)=g(x),
$$

where $\beta_{n}>\beta_{n-1}>\cdots>\beta_{0}$ with $\beta_{n}>0$. We obtain the solution as an infinite series and show its convergence. Furthermore, we investigate this equation with the Riemann-Liouville and Caputo derivatives (non-sequential) instead of distributional ones, and the initial conditions in the classical sense by a new and simpler method. Several interesting applications to solving the fractional differential and integral equations are presented using gamma functions, some of which cannot be achieved by ordinary integral transforms or numerical analysis.

Mathematics subject classification (2010): 46F10, 34A08, 26A33.

Keywords and phrases: Distribution, fractional operator, Mittag-Leffler function, Babenko's approach, variable coefficient, Green's function.

\section{REFERENCES}

[1] Figueiredo Camargo, R., Charnet, R. and Capelas de Oliveira, E., On some fractional Green's functions, J. Math. Phys. 50, 043514 (2009); doi: 10.1063/1.3119484.

[2] Meshrov S.I., Viscoelastic properties of metals, Metallurgia, Moscow, 1974.

[3] Naimark M.A., Linear Differential Operators, Nayka, Moscow, 1969.

[4] Miller, K.S., Ross, B., Fractional Green's functions, Indian J. Pure Appl. Math. 22 (1991), $763-$ 767.

[5] Morita T. And Sato K., Solution of fractional differential equations in terms of distribution theory, Interdisciplinary Information Sciences. 12 (2006), 71-83.

[6] Morita T. And Sato K., Neumann-series solution of fractional differential equation, Interdisciplinary Information Sciences. 16 (2010), 127-137.

[7] Podlubny, I., The Laplace transform method for linear differential equations of the fractional order, Inst. Exp. Phys., Slovak Acad. Sci. UEF-02-94 (1994), 1-32.

[8] Podlubny, I., Fractional Differential Equations, Academic Press, New Yor, 1999.

[9] Hilfer R., LuchKo Y. AND TOMOVsKi Z., Operational method for the solution of fractional differential equations with generalized Riemann-Liouville fractional derivatives, Fract. Calc. Appl. Anal. 12 (2009), 299-318.

[10] Hu Y., LUO Y. AND Lu Z., Analytical solution of the linear fractional differential equation by Adomian decomposition method, J. Comput. Appl. Math. 215 (2008), 220-229.

[11] HUANG X. AND LU X., The use of fractional B-splines wavelets in multiterms fractional ordinary differential equations, Inter. J. Differ Equ. Volume 2010, Article ID 968186, 13 pages.

[12] Kilbas A.A., Rivero M., Rodrignez-Germa L. and Trujillo J.J., $\alpha$-Analytic solutions of some linear fractional differential equations with variable coefficients, Appl. Math. Comput. 187 (2007), 239-249.

[13] Kim, M.H. AND O, H.C., Explicit representation of Green's function for linear fractional differential operator with variable coefficients, J. Fract. Calc. Appl., 5 (2014), 26-36. 
[14] PaK S., Choi H. AND Sin K., Representation of solutions of linear inhomogeneous Caputo fractional differential equation with continuous variable coefficient by Green function, Fract. Differ. Calc. 7(2017), 357-369.

[15] Gel'Fand, I.M. And G.E. Shilov, G.E., Generalized Functions, Vol I, Academic Press, New York, 1964.

[16] Cheng, L. AND Li, C.K., A commutative neutrix product of distributions on $R^{m}$, Math. Nachr. 151 (1991), 345-355.

[17] LI, C.K., A review on the products of distributions. In Mathematical Methods in Engineering; Tass, K., Tenreiro Machado, J.A., Baleanu, D., Eds., Springer: Dordrecht, The Netherlands, 2007, pp. 71-96.

[18] FISHER, B. AND TAŞ, K., The convolution of functions and distributions, J. Math. Anal. Appl. 306 (2005), 364-374.

[19] LI, C.K., Several results of fractional derivatives in $\mathscr{D}^{\prime}\left(R^{+}\right)$, Fract. Calc. Appl. Anal. 18 (2015), 192-207.

[20] LI, C.K. AND LI, C.P., On defining the distributions $\delta^{k}$ and $\left(\delta^{\prime}\right)^{k}$ by fractional derivatives, Appl. Math. Comput. 246 (2014), 502-513.

[21] Li, C.K. AND Clarkson, K., Babenko's approach to Abel's integral equations, Mathematics 2018, 6, 32; doi:10.3390/math6030032.

[22] LI, C.K. AND LI, C.P., Remarks on fractional derivatives of distributions, Tbilisi Mathematical Journal (TMJ) 10 (2017), 1-18.

[23] Babenko, Yu. I., Heat and mass transfer, Khimiya, Leningrad, 1986 (in Russian).

[24] Kilbas, A.A., SrivastaVa, H.M., Trujillo, J.J., Theory and Applications of Fractional Differential Equations, Elsevier, North-Holland, 2006.

[25] Srivastava, H.M., Buschman, R.G., Theory and Applications of Convolution Integral Equations, Kluwer Academic Publishers: Dordrecht, The Netherlands; Boston, MA, USA; London, UK, 1992.

[26] Podlubny, I., Analytical solution of linear differential equation of the fractional order, Comput. Appl. Math. (1994), 102-106. 